\title{
The Right to Be Forgotten Should Not Be Enshrined in Chinese Law
}

\author{
Peng Xiao \\ School of Foreign Studies, Zhongnan University of Economics and Law, Wuhan,China \\ Haoran Lin \\ Law School, Sun Yat-Sen University, Guangzhou, China
}

\begin{abstract}
The emergence of the right to be forgotten not only triggered a heated debate between the European Union (EU) and the United States (US), but also caused quite a stir in China's judicial and legal theory circles. While academics from the UK and the US are wary of the right to be forgotten, their Chinese counterparts are fairly optimistic that this right can be transplanted to China. It is found that remarks such as "introducing the right to be forgotten", “establishing personal information rights”, and "laying down a law on personal information rights” can be frequently observed in relevant studies published in recent years. As an immature new right that has been written into laws of some countries, whether the right to be forgotten is in line with China's practicalities should be cogitated on before it is enshrined in law. Having analyzed what influences the right to be forgotten will exert on China's rule of law and economic development if it is included in China's legal system, a conclusion has been reached. First, the right to be forgotten is detrimental to Chins's advancement of rule of law because it contradicts rights such as freedom of the press, freedom of speech and right to know. Second, it will also inhibit the development of China's burgeoning digital economy. Therefore, the right to be forgotten should not be introduced to or even established in Chinese law at this stage.
\end{abstract}

Keywords: the right to be forgotten, China, rule of law, digital economy

\section{Introduction}

Only if a new legal right originated from one country is suited to another country's national conditions can it be enshrined in the latter's law. The right to be forgotten, ${ }^{1}$ however, is not appropriate for China's practicalities. According to traditional legal theories, legal transplant refers to the moving of a rule or a system of law from one country (region) to another (Shen, 1995, p. 1). Therefore, the introduction of the right to be forgotten into China is in essence a legal transplant. Montesquieu (1989, p. 9) once points out that laws are

Acknowledgements: This research is supported by "the Fundamental Research Funds for the Central Universities”, Zhongnan University of Economics and Law (Grant Number 2722019JCT018).

Peng Xiao, Ph.D., lecturer, School of Foreign Studies, Zhongnan University of Economics and Law, Wuhan, China.

Haoran Lin, research fellow, Law School, Sun Yat-Sen University, Guangzhou, China.

Correspondence concerning this article should be addressed to Peng Xiao, School of Foreign Studies, Zhongnan University of Economics and Law, 182\# Nanhu Avenue, East Lake High-tech Development Zone,Wuhan 430073, China.

${ }^{1}$ For an introduction to the right to be forgotten and the relevant pros and cons debate over its legalization, see Xiao, P., \& Lin, H. R. (2019). The Right to Be Forgotten Debate: Pros and Cons, American Journal of Business, Economics and Management, 7(1), 40-43. 
closely connected with the geography, residents' lifestyles, cultural customs and traditions, religions, etc. of a country and nation. It is rare that one country's law can be applied to another country. Legal transplant is quite a complex process either theoretically or practically and either viewed from history or reality. Its appropriateness hinges on whether a new law is suitable for a country. As an ancient Chinese proverb goes, "tasty tangerines that are grown in southern China will turn sour once they are grown in the north.”2 If a law is blindly transplanted to a new country without taking that country's national conditions into consideration, then it would be converted to a piece of waste paper despite the government's good intention and advanced systems. This can be testified by one example. At the end of the Qing dynasty, the government enacted the Bankruptcy Law even if national industries were under developed at that time. The law turned out to be unavailing.

Therefore, indiscriminate legal transplant should be avoided. To investigate whether the right to be forgotten can be applied in China, China's legal system as well as economic, political, cultural, and social development should be taken into consideration. As Su (1996, p.17) commented, "China must develop the rule of law into a system in the modern times based on its own national conditions." Due to differences in national conditions, the right to be forgotten that emanated from Europe may not be universally applicable. In this article, China's rule of law and economic development will be probed into to analyze whether the right to be forgotten matches China's demands. It is the author's contention that if the right to be forgotten is to be introduced to China's laws hastily at the current stage, it will be detrimental to both the advancement of rule of law and economic growth.

\section{The Right to Be Forgotten Is Not Suitable for China's Advancement of Rule of Law}

The soil of rule of law enables the growth of the tree of rights; every right of citizens is rooted in a sound legal system. The right to be forgotten is closely connected with rights, such as the right to privacy, the right to know, freedom of speech and freedom of the press. Freedom of speech and freedom of the press guarantee the right to know. The right to know and the right to privacy distinguish between public and private information to balance the right to access public information and the right to privacy. The right to be forgotten will not only severely infringe on freedom of speech and freedom of the press, but also blur the boundary between private information and public information. Thus, the balance of rights will swing in favor of the right to privacy. In the meantime, the right to be forgotten allows people to withdraw information that has entered the public domain, which goes against lawmakers' intention of establishing the right to privacy. To put it differently, if the right to be forgotten is transplanted into the Chinese legal system, it will contend for nourishment that should have been obtained by freedom of speech, freedom of the press and the right to know, and thereby break the balance among Chinese citizens' rights, contributing to a twisted and abnormal tree of rights, as shown in Figure 1 below:

\footnotetext{
2 "Master Yan's visit to the State of Chu as an Envoy" in Volume 6 of the Spring and Autumn Annals of Master Yan. Yan Ying. The Spring and Autumn Annals of Master Yan (Yanzi Chunqiu) (Volume 6) (printed in red and black by Ling Chengchu at Wuxing in the Ming dynasty). Commented and proofread by Ling Zhilong. p. 8.
} 


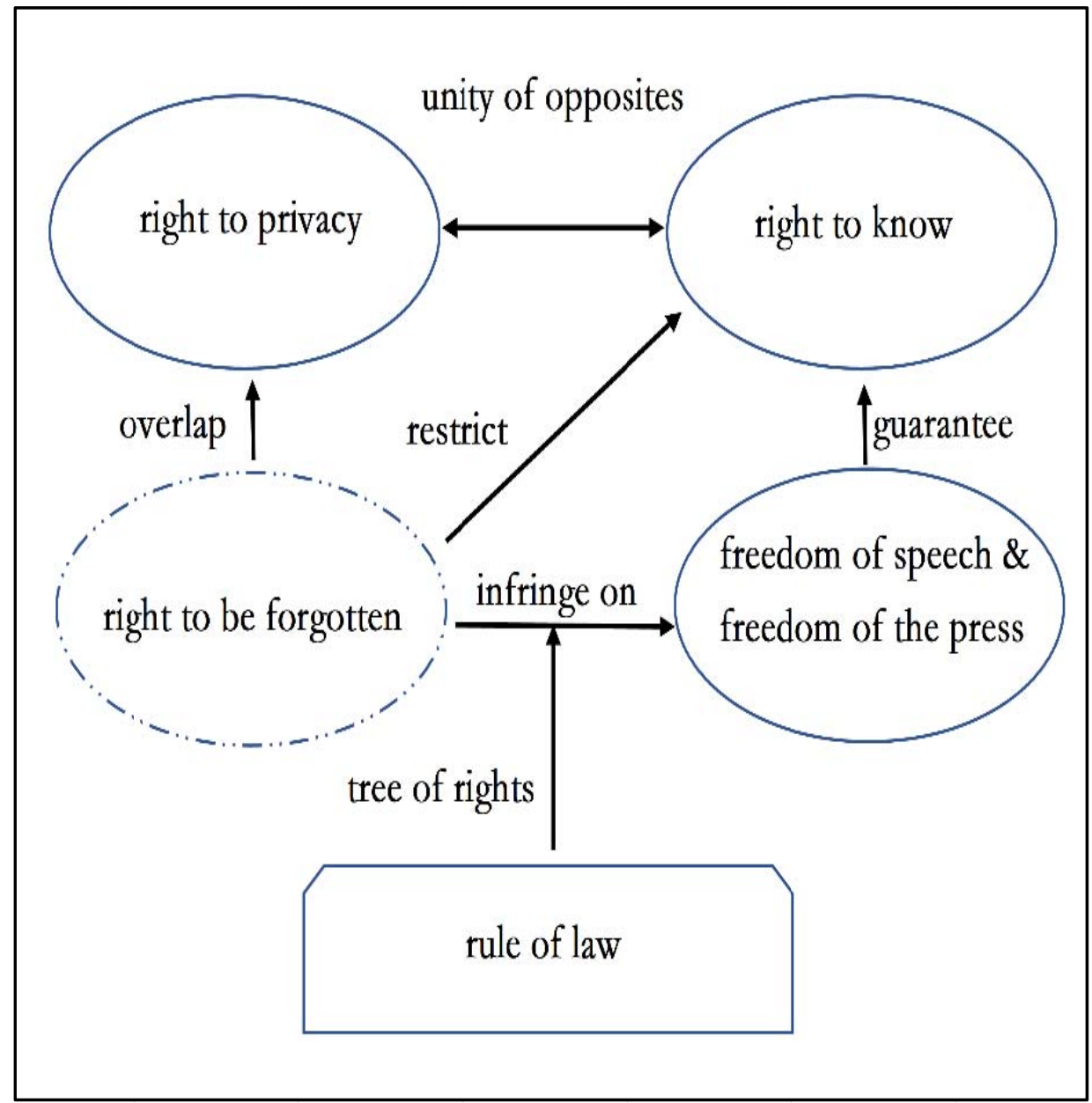

Figure 1. The tree of rights pertinent to the right to be forgotten.

The conflicts between the right to be forgotten and other rights, such as the right to know, freedom of speech and freedom of the press, are exactly the reason why most American academics reject the right to be forgotten. It can be concluded from the totally different attitudes of European and American academics to the right to be forgotten that a country must deliberate on its national conditions before it introduces a legal right. For example, in the European history, Gestapo ${ }^{3}$ and Stasi ${ }^{4}$ were employed to maintain control over the public by monitoring individual information, which had anextremely adverse impact on the society. Therefore, European citizens specially emphasize privacy protection in fear of authoritarianism. By contrast, the Americans lay more stress on freedom of speech because the US was founded amid a wave of protests against

\footnotetext{
3 The Geheime Staatspolizei (Secret State Police), abbreviated Gestapo, was controlled by the Schutzstaffel. At the beginning of its establishment, it was a secret police agency. Then it worked with the Schutzstaffel to jointly implement the plan to exterminate the Jews of Europe. In response to the Nazi's demands, Gestapo developed into a most feared organization. The Nazi made use of Gestapo to keep Germany and countries it occupied under control.

${ }^{4}$ The Ministerium für Staatsicherheit (Ministry for State Security), abbreviated Stasi, was the secret police agency of the German Democratic Republic (East Germany). It was established on February 8, 1950 and headquartered in Eastern Berlin. It served as East Germany's political police and was responsible for intelligence gathering, eavesdropping and surveillance, as well as counterintelligence. It was one of the most hated and feared institutions of the East German communist government and deemed as one of the most powerful intelligence and secret police agencies in the world.
} 
the UK. In other words, the opposite positions on the right to be forgotten between the EU and the US are attributed to disparate historical traditions and national conditions.

Therefore, to determine whether the right to be forgotten is appropriate for China, it is necessary to examine to which degree Chinese people's right to know, freedom of speech and freedom of the press were protected in history.

(1) The right to know. During the thousand-year-long history of feudalism in China, the ruling class implemented a policy of fooling commoners based on the philosophy of Confucius that "the common people shall be made to follow it but not be made to understand it". ${ }^{5}$ This gave rise to a government-dominated information model where the upper class monopolized information and commoners' right to know was neglected. The government was vying with the public for information. After the People's Republic of China was founded and especially since the Third Plenary Session of the 11th Central Committee of the Communist Party of China, the Chinese government has followed the trend of the times to establish and perfect systems for open government information suited to its national conditions. On January 17, 2007, the Regulations on Open Government Information of the People's Republic of China were approved at the 165th meeting of the State Council Standing Committee and came into effect on May 1, 2008. ${ }^{6}$ The regulations received positive social feedback and signaled that the disclosure of government information became a legal obligation. Some academics, however, claim that these regulations are aimed at regulating the government's behavior and advancing administration pursuant to law instead of safeguarding the right to know (Luo, 2017, p. 87). There are also some problems in practice, which have been dealt with in the Regulations on Open Government Information of the People's Republic of China revised in 2019. ${ }^{7}$ The revision enables Chinese citizens to enjoy better protection of the right to know. On the contrary, the right to be forgotten hinders information communication and weakens the right to know because it will be more difficult for the public to find out the truth if data subjects with an ignominious past are allowed to withdraw relevant information from the public domain. As it is observed by the American reporter Lippmann (2006, p. 243), by exercising the right to be forgotten, historical content containing personal data can be erased. This will close the window through which the public get to know the society, leading to cracks and even abnormity in people's perception of the society.

(2) Freedom of speech. In China's history, it is not rare that the ruling class strived to consolidate its position and stabilize the social order at the cost of freedom of speech. For example, in the Qin dynasty, "those who in conversation dare to quote the Book of Songs (Shi Jing) and the Book of Documents (Shang Shu) should be publicly executed; those who use old precedents to oppose the new order should have their families wiped out.” ${ }^{\prime \prime}$ In the Han dynasty, the government "dismisses the other schools of thought and reveres only

\footnotetext{
${ }^{5}$ Confucius. "Taibo" in Book VIII of the Analects (Lun $\mathrm{Yu}$ ).

6 The Regulations on Open Government Information of the People’s Republic of China, Order No. 492 of the State Council of the People's Republic of China.

7 The newly revised Regulations on Open Government Information of the People's Republic of China was officially released on April 15, 2019. The revision has improved systems for open government information in two aspects. First, the government should disclose more public information proactively and adhere to the principle that information is to be withheld only in exceptional circumstances. The government should disclose any information that can be publicized to meet the public's legitimate demands. Second, the government should balance interests of all members of society. It should not only guarantee that the public can have access to government information legally, but also protect state secrets, business secrets, and individual privacy. In the meantime, it should prevent applicants from improper exercise of the right to gain access to government information with an adverse impact on the disclosure of government information. Wan, J. \& Liu, Z. Y. Spokesman of the Ministry of Justice answered the press' questions about the newly revised Regulations on Open Government Information. Legal Daily. 2019-04-16 (2).

${ }^{8}$ Sima Qian, “The Basic Annals of the First Emperor of Qin (Qin Shi Huang)” in the Records of the Grand Historian (Shi Ji).
} 
Confucianism”. 9 In the Ming and Qing dynasties, the literary inquisition prevailed. ${ }^{10}$ There are too many examples to enumerate here. Since the Third Plenary Session of the 11th Central Committee of the Communist Party of China, the central government has made stronger efforts to advance democracy and rule of law, which has provided better legal and economic protection for freedom of speech stipulated in the constitution. Entering the 21st century characterized by an information society, with the rapid development of advanced technologies such as computer and Internet technologies, every Chinese citizen can exchange information on platforms such as WeChat moments, official accounts, QQ space, and Sina Weibo. When Le Yucheng, Vice Minister of Foreign Affairs of China, attended the third round of Universal Periodic Review for China of the United Nations Human Rights Council, he stated that "China has 800 million netizens, around 12,000 kinds of newspapers and journals, over 400 million active Sina Weibo users, and up to 30 billion information entries generated by netizens every day. It is safe to say that China produces the largest amount of information in the world and boasts the richest and most dynamic thoughts in the world" (Fang, 2018). Nonetheless, if the right to be forgotten is introduced into China, then those who harbor evil intentions and behave badly can retract statements and comments disadvantageous to them under legal protection, and Chinese citizens' freedom of speech will be violated.

\section{The Right to Be Forgotten Does Not Satisfy China's economic Development Demands}

On August 31, 2015, the Chinese State Council issued the Action Outline for Promoting the Development of Big Data. In this outline, it is declared that big data has become a new driving force for economic transformation, a new opportunity that reshapes a country's competitive edge, and a new approach that improves governance capacity. ${ }^{11}$ In September 2016, the Digital Economy Development and Cooperation Initiative was passed at the G20 Hangzhou summit ${ }^{12}$ and marks the first digital economy-related document jointly signed by multipleheads of state. On March 5, 2017, Premier Li Keqiang delivered the Government Work Report to the fifth session of the 12th National People's Congress. He noted that the government would boost the digital economy and deliver benefits to all businesses and the public (the General Office of the State Council, 2017). For the first time, digital economy was mentioned in a government work report. "China's digital economy is embracing the best era," remarked Ben Shenglin, Professor of School of Management and dean of Academy of Internet Finance at Zhejiang University (Lv, 2017).

The subject of obligation of the right to be forgotten is the data controller. In the Internet era, the major subjects that collect personal data are different types of search engine companies and social media websites. Europe and the US have demonstrated distinct stance and attitudes on the right to be forgotten. The EU has

\footnotetext{
${ }^{9}$ Dong Zhongshu (179-104 BC) proposed to revere only Confucianism and dismissed all the hundred schools of thought in 134 $\mathrm{BC}$ and this philosophy was put into practice during Emperor Wu of Han's reign.

${ }^{10}$ The literary inquisition refers to official persecution of intellectuals for their writings in imperial China. It took place under each of the dynasties ruling China, although the Qing dynasty was particularly notorious for the practice. Moreover, it was during the Qianlong Emperor's reign that the inquisition reached its climax. As the Chinese historian Gu Jiegang observes, "During the 300 years' history of the Qing dynasty, only few studies on the literary inquisition have been preserved. Is there any literature that can attest to the existence of the literary inquisition in other dynasties? Yes, but the cruelty of inquisition at the beginning of the Qing dynasty is unparalleled.”

${ }^{11}$ The State Council. Notice of the State Council on Issuing the Action Outline for Promoting the Development of Big Data (No. 50 [2015] of the State Council). The website of the Chinese government, 2015-09-05. Retrieved from http://www.gov.cn/zhengce/content/2015-09/05/content_10137.htm.

${ }^{12}$ G20 Digital Economy Development and Cooperation Initiative. The website of the Cyberspace Administration of China, 2016-09-29. Retrieved from http://www.cac.gov.cn/2016-09/29/c_1119648520.htm.
} 
legislated for the right to be forgotten in forms of law and judicial precedent while the US has not established it as a legal right in a form of either law or judicial precedent except for the Eraser Law passed by the state of California $^{13}$.

The root causes lie in different national conditions and interests: the US is home to Internet giants such as Google and an Internet industrial cluster while Europe is not; the target of the EU's legislation on the right to be forgotten as well as judicial decisions resembles personal information in the information industry of the US (Song, 2016, p. 24). China, similar to the US, has many Internet companies represented by Baidu, Tencent, Sina, and NetEase, which will also be impacted by the right to be forgotten. Nonetheless, these businesses are leaders in China's digital economy. Once the right to be forgotten is introduced into China, the aforementioned companies will have to spend considerable time, money, and manpower in fulfilling the obligation of reviewing information and speech imposed by this right. This will reduce their operational efficiency and thereby slow down the development of digital economy. On the other hand, by erasing a large quantity of data in the digital world, the right to be forgotten will also hamper big data analysis conducted in a variety of industries. As pointed out by the Chief Data Officer Alliance, "If big data is made good use of, it will boost the economy; vice versa” (Liu \& Lu, 2017, p. 8).

At present, digital technologies are closely linked with our lives and bringing us unprecedented convenience. Tu (2015, pp.15-16), a famous information management expert, maintains that data-based innovation will enable every field in human society to improve in leaps and bounds, which is beyond the imagination of our forefathers. At the same time, he exemplifies various fields including agriculture, education, healthcare, manufacturing, and finance with examples to illustrate benefits and opportunities brought by digital technologies to the mankind. Admittedly, the development of digital technologies is sure to inconvenience the public to some extent. As the Intermediate People's Court of Nanjing Municipality states in the judgment of the case inw hich Zhu Ye sues Baidu, "As Internet users enjoy Internet services freely, they should be more tolerant of the inconvenience brought by the personal recommendation service". ${ }^{14}$ When people relish numerous benefits generated by digital technologies, it is inevitable that they need to renounce a small part of their information rights.

\section{Conclusion}

Ever since human beings began to use their brains, they have been glorifying memory and resisting oblivion. The diversified and magnificent human civilizations stem from our forefathers' memorizing, sharing, calculating, and inheriting a great wealth of information. The big data era that we are now in, just like every information revolution in history, represents natural technological advancement as well as an unstoppable trend of the times. Although every revolutionary discovery and leap in human history is accompanied by ravings and warnings, in terms of the big data technology that benefits humans a lot, we should not bind ourselves, nor should we compel it to stagnate and even retrogress through legislation.

\footnotetext{
13 The California SB 568 was passed in 2013 and came into effect on January 1, 2015, known as the Eraser Law. As required by the Eraser Law, social networking giants, including Facebook and Twitter, should permit minors to erase materials they posted on the Internet to avoid the lingering network traces in the future due to lack of awareness of cybersecurity.Stats. 2013, Ch. 336, (SB 568).

${ }^{14}$ Zhu Yev. Baidu. Intermediate People’s Court of Nanjing Municipality. 2014-Ning-Min-Chu-Zi-5028.
} 
Having ruminated over the advantages and disadvantages, Chinese lawmakers should prefer to bolster China's digital economy that is in the ascendant rather than introduce the right to be forgotten that is still immature and incorporated in personal information rights.

\section{References}

Fang, Y. X. (2018). Le Yucheng, Vice Minister of Foreign Affairs of China: There is also a red line in freedom of speech. People.cn. 2018-11-07. Retrieved from http://world.people.com.cn/n1/2018/1107/c1002-30385764.html

Lippmann, W. (2006). Public opinion (K. W. Yan, Trans.). Shanghai: Shanghai People’s Publishing House.

Liu, D. D., \& Lu, S. H. (2017). Empowering the digital economy: Innovation and entrepreneurship using big data. Beijing: The People's Posts and Telecommunications Press.

Luo, Y. (2017). A comparison of Chinese and Japanese government information disclosure system under the background of big data: From a right-to-know perspective. Journal of Chongqing University (Social Science Edition), 1, 86-93.

Lv, B. (2017). Ben Shenglin from School of Management, Zhejiang University: China's digital economy is facing the best age. www.nen.com.cn. 2017-12-08. Retrieved from http://pj.nen.com.cn/system/2017/12/08/020240914.shtml

Montesquieu, C. (1989). The spirit of the laws (A. M. Cohler, B. C. Miller, \& H. S. Stone, Trans.). New York: Cambridge University Press.

Shen, Z. L. (1995). Legal transplant and comparative law. Global Law Review, 1, 1-7.

Song, T. (2016). Can the right to be forgotten be incorporated into the Civil Code?-An interview with Judge Chen Changyi. Democracy and Legal System, 34, 23-28.

Su, L. (1996). Rule of law and its local resources. Beijing: China University of Political Science and Law Press.

The General Office of the State Council. (2017). Government Work Report 2017. Beijing: People’s Publishing House.

Tu, Z. P. (2015). Big data: The upcoming data revolution and how it changes the government, businesses and our lives. Guilin: Guangxi Normal University Press.

Xiao, P., \& Lin, H. R. (2019). The right to be forgotten debate: Pros and cons. American Journal of Business, Economics and Management, 7(1), 40-43. 